\title{
Correction to: Advances in Understanding the Biology of Halophilic Microorganisms
}

\author{
Russell H. Vreeland
}

\section{Correction to:}

\author{
R. H. Vreeland (ed.), Advances in Understanding the \\ Biology of Halophilic Microorganisms, \\ DOI 10.1007/978-94-007-5539-0_3
}

In the original version of chapter 3, two chapter authors' first name and last name were tagged incorrectly. The book has been updated with the correct author names.

The name of the authors should read as follows,

"de la Haba, Rafael R", where "de la Haba" is last name and "Rafael R." is first name.

"Márquez, M. Carmen", where "Márquez" is last name and "M. Carmen” is first name.

The updated online version of the original book can be found at DOI 10.1007/978-94-007-5539-0_3 